\title{
Pengaruh Pelatihan Manajemen Penyuluhan Terhadap Kinerja Tenaga Harian Lepas Tenaga Bantu Penyuluh Pertanian (THL-TBPP) Di Sumatera Barat
}

\author{
${ }^{1}$ Rinofi, ${ }^{2}$ Eva Manjas \\ ${ }^{12}$ UPTD Balai Pelatihan dan Penyuluhan Pertanian Sumatera Barat \\ e-mail :udo_ryno@yahoo.co.id
}

\begin{abstract}
Abstrak
Pada tahun 2019, jumlah THL-TBPP di Sumatera Barat adalah sebanyak 536 orang yang terbagi atas THLTBPP dari dana APBN sebanyak 399 orang dan dana APBD sebanyak 137 orang. Dalam rangka meningkatkan kinerja penyuluh dalam melaksanakan program penyuluhan, diperlukan upaya peningkatan kompetensi penyuluh THL-TBPP, salah satunya dapat diperoleh melalui pelatihan. Penelitian ini bertujuan untuk menganalisa pengaruh pelatihan terhadap kinerja Tenaga Harian Lepas-Tenaga Bantu Penyuluh Pertanian (THL-TBPP) di Provinsi Sumatera Barat. Metode penelitian ini menggunakan pendekatan survei dengan metode kuantitatif. Teknik analisis data menggunakan analisis deskriptif dan analisis induktif. Hasil penelitian ini menunjukkan bahwa pelatihan manajemen penyuluh THL-TBPP pada aspek materi diklat, fasilitator, dan penyelenggaraan diklat telah terlaksana dengan sangat baik. Kinerja penyuluh THL-TBPP mulai dari persiapan penyuluhan, pelaksanaan penyuluhan, hingga evaluasi dan pelaporan sangat tinggi di mana penyuluh THL-TBPP melaksanakan semua pekerjaan tersebut dengan sangat baik. Pelatihan memiliki tingkat signifikansi sebesar $0,000<0,05$, sehingga memenuhi syarat menjadi variabel pendukung kinerja penyuluh. Hal ini berarti bahwa jika kinerja penyuluh THL-TBPP di Sumatera Barat meningkat, maka hal ini disebabkan salah satunya oleh pelatihan yang dilaksanakan. Saran terhadap penelitian ini adalah agar pelatihan yang diselenggarakan untuk penyuluh THL-TBPP dapat terus dipertahankan baik dari segi kualitas maupun kuantitas. Selanjutnya, dalam upaya peningkatan kinerja penyuluh THL-TBPP, perhatian terhadap hal-hal yang berkaitan dengan pelatihan penyuluh agar dapat terus dipertahankan oleh pemangku kebijakan.
\end{abstract}

Kata Kunci : Pelatihan, Kinerja THL-TBPP.

Abstrack
In 2019, the number of THL-TBPP in West Sumatra was 536 people, divided into 399 THL-TBPP from $A P B N$ funds and 137 people from APBD funds. In order to improve the performance of extension workers in implementing extension programs, efforts are needed to increase the competence of THL-TBPP extension workers, one of which can be obtained through training. This study aims to analyze the effect of training on the performance of the daily off-duty agricultural extension assistants (THL-TBPP) in West Sumatra Province. This research method uses a survey approach with quantitative methods. The data analysis technique used descriptive analysis and inductive analysis. The results of this study indicate that the THL-TBPP extension management training on the aspects of training materials, facilitators, and the implementation of education and training has been carried out very well. The performance of THL-TBPP extension workers, from preparation of extension, implementation of extension, to evaluation and reporting was very high, where the THL-TBPP extension officers carried out all of this work very well. The training has a significance level of $0.000<0.05$, so it qualifies to be a variable supporting the performance of the instructor. This means that if the performance of THL-TBPP extension workers in West Sumatra increases, this is due to the training being carried out in one way. The suggestion for this research is that the training held for THL-TBPP extension workers can be maintained both in terms of quality and quantity. Furthermore, in an effort to improve the performance of THL-TBPP extension workers,

Keywords: Training, THL-TBPP Performance 


\section{PENDAHULUAN}

Penyuluh merupakan individu yang bertugas mempengaruhi proses pengambilan keputusan sasaran untuk mengadopsi suau inovasi yang diberikan. UU No. 16/2006 menyebutkan penyuluh adalah perorangan, WNI bisa Pegawai Negeri Sipil, penyuluh swasta dan penyuluh swadaya. Sedangkan Permen PAN No. 2/2008 menegaskan Penyuluh Pertanian adalah Jabatan Fungsional yang memiliki ruang lingkup tugas, tanggung jawab dan wewenang penyuluhan pertanian yang diduduki oleh Pegawai Negeri Sipil yang diberi hak serta kewajiban secara penuh oleh pejabat yang berwenang.

Kegiatan penyuluhan tidak hanya dilakukan oleh penyuluh PNS saja. Karena kekurangan tenaga penyuluh, pada tahun 2007 pemerintah melalui Kementerian Pertanian mengangkat Tenaga Harian Lepas-Tenaga Bantu Penyuluhan Pertanian (THL-TBPP) untuk membantu kegiatan penyuluhan. Tabel 1.1 menunjukkan jumlah THL-TBPP di Provinsi Sumatera Barat. THL-TBPP yang direkrut dari tahun 2007-2009, sampai saat ini sudah bekerja selama 7-10 tahun. Dalam melaksanakan tugasnya, THL-TBPP belum mendapatkan pelatihan bidang substansi penyuluhan yang sama dengan penyuluh PNS. Data Balai Diklat Pertanian Sumatera Barat menyatakan bahwa THL-TBPP hanya dibekali dengan satu kali pelatihan pembekalan penyuluh, akan tetapi belum dibekali dengan pelatihan dasar, pelatihan fungsional penyuluhan terampil dan ahli seperti yang didapat penyuluh PNS sesuai dengan tugasnya.

Dalam rangka melaksanakan program penyuluhan dengan baik maka perlu adanya upaya peningkatan kompetensi, salah satunya dapat diperoleh melalui pelatihan. Pelatihan merupakan kegiatan pembelajaran untuk meningkatkan kompetensi kerja individu agar mampu berprestasi dalam tugas dan jabatannya. Meningkatnya kompetensi kerja individu hanya akan terjadi apabila adanya perubahan aspek perilaku kognitif, afektif dan psikomotorik. Untuk itu, diperlukan program diklat yang dirancang berbasiskan kompetensi kerja atau dikenal dengan CBT (Competency Based Training).

Kinerja THL-TBPP di Provinsi Sumatera Barat diduga dipengaruhi oleh pelatihan. Simamora (2004) mengartikan pelatihan sebagai rangkaian aktivitas yang dirancang dalam rangka peningkatan kemampuan, keahlian, pengetahuan, pengalaman, hingga perubahan sikap dan perilaku seseorang. Pelatihan juga disebutkan sebagai proses belajar mengajar yang sistematis dan terorganisir dalam rangka memperbaiki performa individu karyawan dalam pekerjaan yang menjadi tanggung jawabnya (Gomes, 2000; Asnawi, 2002).

Tujuan penelitian (1) Mendeskripsikan Pelatihan Manajemen Penyuluhan Pertanian bagi THLTBPP di Provinsi Sumatera Barat. (2) Mendeskripsikan Kinerja penyuluh THL-TBPP di Provinsi Sumatera Barat. (3) Menganalisis pengaruh pelatihan terhadap kinerja THL-TBPP di Provinsi Sumatera Barat.

\section{METODE}

Penelitian ini menggunakan metode kuantitatif dengan pendekatan survei. Metode penelitian kuantitatif bertujuan menguji suatu teori dengan cara menguji hubungan atau pengaruh antar variabel penelitian dengan menggunakan intrumen penelitian berupa kuesioner yang terdiri atas angka-angka yang dapat diukur secara statistik. Sementara itu, penelitian dengan pendekatan survei berusaha memaparkan secara kuantitatif kecenderungan, sikap, atau opini dari suatu populasi tertentu dengan meneliti satu sampel dari populasi tersebut (Creswell, 2010).

Populasi merupakan kelompok elemen lengkap berupa orang, objek transaksi, atau kejadian dimana kita tertarik mempelajarinya atau menjadi objek penelitian (Arikunto, 2009). Populasi dari penelitian ini merupakan keseluruhan peserta pelatihan manajemen penyuluhan bagi THL-TBPP tahun 2016 sampai 2017 sebanyak 120 orang di Sumatera Barat. Sampel merupakan bagian populasidalam suatu penelitian (Sugiyono, 2007).Metode penarikan sampel pada penelitian ini menggunakan sampling probabilitas 
dengan Proportional Random Sampling, yaitu penarikan sampel secara sampel acak anggota populasi dan dilakukan dengan mengambil persentase proporsional dari jumlah populasi.

\section{Tabel 1. Difinisi Oprasional}

\begin{tabular}{|c|c|c|c|}
\hline $\begin{array}{l}\text { Variabel } \\
\text { penelitian }\end{array}$ & Sub Variabel & Indikator & Pengukuran \\
\hline \multirow[t]{4}{*}{$\begin{array}{l}\text { Kinerja } \\
(\mathrm{Y})\end{array}$} & Persiapan penyuluhan & & Skala Ordinal \\
\hline & a)Membuat Data Potensi & $\begin{array}{l}\text { Ketersediaan data potensi wilayah dan } \\
\text { agroekosistempadawilayahbinaan. }\end{array}$ & \\
\hline & $\begin{array}{l}\text { b)Memandu (pengawalan } \\
\text { dan pendampingan) } \\
\text { Penyusunan RDKK }\end{array}$ & $\begin{array}{l}\text { Memberikan bimbingan pada kelompok tani } \\
\text { binaanmenyusun RDKK (Rencana Definitif } \\
\text { Kebutuhan Kelompok) mulai dari perumusan } \\
\text { rencana usaha kelompok/rencana usaha bersama } \\
\text { (RUK/RUB),Merumuskan Rencana Definitif } \\
\text { Kelompok (RDK), merumuskanRencanaDefinitif } \\
\text { KebutuhanKelompok (RDKK), danmerumuskan } \\
\text { RDKK pupukbersubsidisesuaidengankebutuhannya. }\end{array}$ & \\
\hline & $\begin{array}{l}\text { c)Penyusunan Programa } \\
\text { Penyuluhan }\end{array}$ & $\begin{array}{l}\text { Keterlibatan penyuluh dalam menyusun } \\
\text { programa penyuluhan. }\end{array}$ & \\
\hline \multirow[t]{5}{*}{$\begin{array}{l}\text { Pelatihan } \\
(\mathrm{X})\end{array}$} & Materi diklat & & Skala Ordinal \\
\hline & $\begin{array}{l}\text { A) Dasar-Dasar Penyuluhan } \\
\text { pertanian }\end{array}$ & $\begin{array}{l}\text { Penguasaanresponden terhadap materi kelompok inti } \\
\text { yang dipelajari pada pelatihan Manajemen Penyuluhan } \\
\text { Pertanian Bagi THL-TBPP. }\end{array}$ & \\
\hline & $\begin{array}{l}\text { B) Tugas Pokok dan Fungsi } \\
\text { Penyuluhan Pertanian. } \\
\text { C) Identifikasi Potensi } \\
\text { Wilayah. } \\
\text { D) Programa Penyuluhan } \\
\text { Pertanian. }\end{array}$ & & \\
\hline & 1) Fasilitator & & Skala Ordinal \\
\hline & $\begin{array}{l}\text { Penguasaan Materi } \\
\text { (pengetahuan keterampilan) } \\
\text { Penguasaan Metoda } \\
\text { (kemampuan berkomunikasi } \\
\text { menjawab pertanyaan) } \\
\text { ) Kemampuan Menggunakan } \\
\text { alat bantu (pengunaan } \\
\text { sarana) }\end{array}$ & $\begin{array}{l}\text { Penilaian respon terhadap kemampuan fasilitator } \\
\text { pada pelatihan Manajemen Penyuluhan } \\
\text { Pertanian Bagi THL-TBPP }\end{array}$ & \\
\hline
\end{tabular}

\section{HASIL DAN PEMBAHASAN}

\section{A. Pelatihan Manajemen Penyuluhan Pertanian}

Kegiatan pelatihan manajemen penyuluhan pertanian yang diterima oleh penyuluh THL-TBPP merupakan bagian dari serangkaian kegiatan pendidikan dengan tujuan memperbaiki dan mengembang aspek kognitif, afektif, dan konatif penyuluh THL-TBPP dalam mendukung aktivitas penyuluhan di wilayah kerja mereka. Seperti yang juga tertuang dalam Permentan No. 1 Tahun 2008, kegiatan pelatihan merupakan bagian dari pembekalan THL-TBPP sebelum diturunkan langsung ke lapangan. 
Tabel 1

Distribusi frekuensi penilaian responden terhadap pelatihan manajemen penyuluhan pertanian.

\begin{tabular}{|c|c|c|}
\hline \multirow{2}{*}{ Kategori } & \multicolumn{2}{|c|}{ THL-TBPP } \\
\hline & Frekuensi (orang) & Persentase (\%) \\
\hline \multicolumn{3}{|c|}{ Pelatihan manajemen penyuluhan pertanian } \\
\hline Cukup & 1 & 1,1 \\
\hline Baik & 16 & 17,4 \\
\hline Sangat Baik & 75 & 81,5 \\
\hline \multicolumn{3}{|l|}{ Penguasaan materi diklat } \\
\hline Cukup & 1 & 1,1 \\
\hline Baik & 14 & 15,2 \\
\hline Sangat Baik & 77 & 83,7 \\
\hline \multicolumn{3}{|l|}{ Kemampuan fasilitator } \\
\hline Cukup & 2 & 2,2 \\
\hline Baik & 14 & 15,2 \\
\hline Sangat Baik & 76 & 82,6 \\
\hline \multicolumn{3}{|l|}{ Penyelenggaraan diklat } \\
\hline Cukup & 0 & 0,0 \\
\hline Baik & 19 & 20,7 \\
\hline Sangat Baik & 73 & 79,3 \\
\hline Jumlah & 92 & 100,0 \\
\hline
\end{tabular}

Selain penguasaan materi, kemampuan fasilitator dalam memberikan materi diklat juga sudah sangat baik. Hal ini terlihat dari beberapa hal seperti a) Penguasaan Materi (pengetahuan keterampilan) fasilitator saat di kelas, b) Penguasaan Metoda (kemampuan berkomunikasi menjawab pertanyaan) fasilitator saat memberikan pelatihan, c)Kemampuan Menggunakan alat bantu (pengunaan sarana) fasilitator seperti pengguaan laptop, infocus, dan sebagainya ketika memberikan materi, d)Penegakan disiplin (kehadiran, kerapian, sikap prilaku) fasilitator terhadap peserta diklat, dan e)Tujuan pembelajaran (Relevansi materi dengan indikator keberhasilan mencapai tujuan) yang diberikan oleh fasilitator. Hasil penelitian menunjukkan bahwa kemampuan fasilitator dalam memberikan materi dan menyelenggarakan diklat sudah sangat baik, sehingga peserta pelatihan termasuk penyuluh THL-TBPP responden dapat menjalankan pelatihan dengan lebih optimal.

\section{B. Penguasaan Materi Diklat}

Berdasarkan hasil distribusi frekuensi yang ditunjukkan oleh Tabel 4.2, penguasaan responden terhadap materi pelatihan yang diberikan dalam kegiatan pelatihan tergolong tinggi, yaitu sebesar 83,7 persen. Hal ini berarti bahwa kemampuan penyuluh THL-TBPP dalam menguasai materi yang diberikan selama pelatihan sangat baik. Kemampuan penyuluh THL-TBPP dalam menyerap materi pembelajaran yang diberikan oleh pemateri di saat pelatihan tergolong sangat baik, sehingga tujuan kegiatan pelatihan seperti yang disebutkan dalam LAN RI (2003) yaitu untuk mengubah kompensi kerja agar dapat beprestasi dengan lebih baik dapat dicapai.

Sebanyak sembilan jenis materi dasar yang diberikan dalam pelatihan dapat dikuasai dengan baik oleh peserta yang merupakan penyuluh THL-TBPP. Penyuluh THL-TBPP menguasai materi dasar-dasar penyuluhan pertanian sebagai pengetahuan dasar mengenai kegiatan penyuluhan yang harus mereka 
kuasai. Hal ini agar penyuluh THL-TBPP dapat melaksanakan tugas dan fungsinya dalam menjalankan tugas di lapangan.

\section{Kemampuan Fasilitator}

Kemampuan fasilitator dalam penguasaan materi, penguasaan metode, kemampuan menggunakan alat bantu, penegakan disiplin oleh fasilitator, hingga tujuan pembelajaran dinilai relatif baik oleh penyuluh THL-TBPP yang menjadi peserta pelatihan. Tabel 4.2 menunjukkan terdapat 76 orang $(82,6 \%)$ responden menilai bahwa kemampuan fasilitator pelatihan manajemen penyuluhan pertanian tergolong sangat baik. Hal ini berarti bahwa fasilitator menguasai materi yang akan diberikan kepada peserta pelatihan, mulai dari dasar-dasar penyuluhan hingga teknik kepemanduan. Materi dan tujuan pembelajaran yang disampaikan oleh fasilitator relevan dengan tujuan yang akan dicapai dalam aktivitas THL-TBPP dalam penyuluhan pertanian. Kemampuan fasilitator dalam menyelenggarakan dan memberikan pelatihan terhadap penyuluh THL-TBPP akan memberikan pengaruh terhadap kinerja penyuluh THL-TBPP di lapangan, seperti temuan Putri et al. (2016) yang menyatakan bahwa pelatihan yang diterima oleh penyuluh akan sangat berguna dan berpengaruh dalam meningkatkan kinerja penyuluh di lapangan.

Hal tersebut menunjukkan bahwa fasilitator sebagai organisasi pembina telah melaksanakan tugasnya sebagai pembina teknis dalam pelatihan yang diberikan untuk meningkatkan kemampuan penyuluh THL-TBPP. Selain itu, kelengkapan admininstrasi dan pelaporan baik sebelum dan sesudah kegiatan, serta dilaksanakannya monitoring dan evaluasi terhadap kinerja penyuluh THL-TBPP sebagai hasil nyata dari kegiatan pelatihan yang diberikan juga telah dilaksanakan dengan baik.

\section{Kinerja Penyuluh THL-TBPP}

Kinerja penyuluh THL-TBPP pada penelitian ini merupakan hasil kerja sesuai dengan tugas yang diembankan kepadanya, di mana dapat dikatakan efektif jika menjalankan tugas dan fungsi sesuai dengan UU yang berlaku. Kinerja penyuluh THL-TBPP diukur melalui kemampuan mereka dalam aktivitas persiapan penyuluhan, pelaksanaan penyuluhan, serta evaluasi dan pelaporan. Secara umum, kinerja penyuluh THL-TBPP tergolong tinggi. Gambaran umum mengenai kinerja responden disajikan pada Tabel 3.

Tabel 2. Kategori kinerja penyuluh THL-TBPP.

\begin{tabular}{|c|c|c|}
\hline \multirow[b]{2}{*}{ Kategori } & \multicolumn{2}{|c|}{ THL-TBPP } \\
\hline & Frekuensi (orang) & Persentase (\%) \\
\hline \multicolumn{3}{|l|}{ Kinerja penyuluh THL-TBPP } \\
\hline Kurang & 0 & 0,0 \\
\hline Baik & 18 & 19,6 \\
\hline Sangat Baik & 74 & 80,4 \\
\hline \multicolumn{3}{|l|}{ Persiapan penyuluhan } \\
\hline Kurang & 0 & 0,0 \\
\hline Baik & 11 & 12,0 \\
\hline Sangat Baik & 81 & 88,0 \\
\hline \multicolumn{3}{|l|}{ Pelaksanaan penyuluhan } \\
\hline Kurang & 0 & 0,0 \\
\hline Baik & 19 & 20,7 \\
\hline Sangat Baik & 73 & 79,3 \\
\hline
\end{tabular}




\begin{tabular}{|c|c|c|}
\hline \multirow[b]{2}{*}{ Kategori } & \multicolumn{2}{|c|}{ THL-TBPP } \\
\hline & Frekuensi (orang) & Persentase $(\%)$ \\
\hline \multicolumn{3}{|c|}{ Evaluasi dan pelaporan } \\
\hline Kurang & 0 & 0,0 \\
\hline Baik & 25 & 27,2 \\
\hline Sangat Baik & 67 & 72,8 \\
\hline Jumlah & 92 & 100,0 \\
\hline
\end{tabular}

Hasil penelitian yang ditunjukkan oleh Tabel 3 memperlihatkan bahwa secara umum, kinerja penyuluh THL-TBPP responden dalam memberikan penyuluhan di lapangan berada pada kategori sangat baik (80,4 persen). Hal ini berarti bahwa kinerja penyuluh THL-TBPP dalam melaksanakan penyuluhan dimulai dari persiapan, pelaksanaan, hingga evaluasi sudah sangat baik. Berdasarkan hasil observasi di lapangan, tingginya kinerja penyuluh THL-TBPP dalam melaksanakan kegiatan penyuluhan disebabkan karena pelaksanaan pelatihan yang diikuti sudah sangat baik, serta motivasi penyuluh THL-TBPP dalam menjalankan pekerjaannya sudah tinggi. Penyuluh THL-TBPP yang sudah memiliki bekal cukup sebagai hasil keikutsertaannya dalam pelatihan manajemen penyuluhan pertanian dapat melaksanakan aktivitas persiapan penyuluhan dengan sangat baik pula. Persiapan tersebut dapat dilihat baik dari segi teknis seperti persiapan materi dan metode penyuluhan, maupun dari segi non teknis seperti kemampuan berkomunikasi, persiapan bahan, sarana dan prasarana yang dibutuhkan.

\section{E. Pengaruh Pelatihan Terhadap Kinerja THL-TBPP}

Pengaruh pelatihan terhadap kinerja THL-TBPP dalam penelitian ini dilakukan dengan uji regresi linear sederhana. Hasil uji statistik pengaruh pelatihan terhadap kinerja disajikan pada Tabel 4.

Tabel 4. Hasil analisa regresi linear .

\begin{tabular}{lccc}
\hline Variabel & Koefisien regresi & $\mathrm{t}_{\text {hitung }}$ & sig. \\
\hline Constant & 18,457 & 3,985 & 0,000 \\
\hline Pelatihan $\left(\mathrm{X}_{1}\right)$ & 0,194 & 4,415 & 0,000 \\
\hline $\mathrm{F}$ & 18,925 & & $0,000^{\mathrm{b}}$ \\
\hline $\mathrm{t}$ table & & 1,98698 & \\
\hline$R$ square & & & 0,283 \\
\hline
\end{tabular}

Berdasarkan hasil olah data penelitian pada Tabel 4.4, kesimpulan yang dapat diambil berupa:

a) Nilai konstanta sebesar 18,457 berarti: tanpa adanya pengaruh dari pelatihan nilai kinerja telah mencapai 18,457 .

b) Koefisien regresi variabel pelatihan (X) sebesar 0,194berarti jika nilai pelatihan meningkat sebesar satu satuan, maka nilai pada kinerja penyuluh THL-TBPP akan meningkat sebesar 0,194dalam setiap satuannya. Artinya, semakin tinggi nilai pelatihan, maka nilai kinerja THL-TBPP dalam melaksanakan kegiatan penyuluhan juga akan semakin besar..

Pelatihan manajemen penyuluhan yang baik, dapat mempengaruhi kinerja penyuluh THL-TBPP dalam menjalankan aktivitas penyuluhan pertanian. Hasil observasi di lapangan menunjukkan hal serupa di mana pelatihan yang diikuti oleh penyuluh THL-TBPP mempengaruhi peningkatan kinerja penyuluh. 
Beberapa temuan menyebutkan, faktor-faktor yang juga ikut mempengaruhi kinerja seperti faktor internal yang ada di dalam diri penyuluh dan faktor eksternal di luar diri penyuluh. Temuan Yuaniarti (2011) menunjukkan bahwa faktor yang turut mempengaruhi kinerja penyuluh adalah karakteristik penyuluh, proses pelatihan, faktor penunjang penyuluhan, faktor lingkungan penyuluh, dan kompetensi penyuluh itu sendiri. Dalam hal ini, temuan Yuniarti (2011) menyebutkan bahwa faktor yang paling kuat mempengaruhi kinerja penyuluh adalah karakteristik diri penyuluh. Hal serupa juga terdapat pada hasil temuan Sapar et al. (2011) dan Wicaksono et al (2016) yang juga menyebutkan bahwa salah satu faktor yang paling mempengaruhi kinerja penyuluh adalah karakteristik diri penyuluh dan kompetensi penyuluh. Hal ini menunjukkan bahwa faktor internal yang paling mempengaruhi kinerja penyuluh pertanian dalam kegiatan penyuluhan adalah karakteristik dirinya, seperti umur, tingkat pendidikan, dan pengalaman kerja

\section{KESIMPULAN}

Penyuluh THL-TBPP umumnya merupakan individu dengan usia dewasa baik laki-laki maupun perempuan, serta umumnya memiliki tingkat pendidikan formal hingga SMA. Pelaksanaan pelatihan manajemen penyuluh THL-TBPP telah terlaksana dengan sangat baik; di mana penguasaan materi diklat oleh penyuluh THL-TBPP berada pada nilai yang paling tinggi. Selanjutnya, kinerja penyuluh THLTBPP di Sumatera Barat dilakukan dengan sangat baik pada setiap aspek kinerja.Pelatihan berpengaruh secara signifikan terhadap kinerja penyuluh THL-TBPP di Sumatera Barat. Pelatihan memiliki tingkat signifikansi sebesar $0,000<0,05$, sehingga memenuhi syarat menjadi variabel pendukung kinerja penyuluh. Hal ini berarti bahwa jika kinerja penyuluh THL-TBPP di Sumatera Barat meningkat, maka hal ini disebabkan salah satunya oleh pelatihan yang dilaksanakan. Pelatihan manajemen penyuluhan pertanian memberikan dampak positif bagi meningkatnya kinerja penyuluh THL-TBPP di Sumatera Barat.

\section{SARAN}

Pelatihan yang diselenggarakan untuk penyuluh THL-TBPP harus dipertahankan kualitas dan kuantitasnya. Pelatihan yang diselenggarakan berupa kegiatan non teknis dan peningkatan kemampuan penyuluh THL-TBPP sesuai dengan kebutuhan dan permasalahan di lapangan. Untuk mempertahankan hal tersebut, perlu dilakukan penguatan anggaran dan kerja sama dengan pihak terkait untuk bidang penyuluhan pertanian. Dukungan lembaga penyuluhan pertanian hendaknya dipertahankan agar dapat selalu bertindak adil dan merata serta tepat sasaran kepada penyuluh THL-TBPP yang memang tidak terlalu banyak mendapatkan kegiatan pelatihan. Hal ini dapat membantu meningkatkan kinerja penyuluh secara maksimal.

Berkaitan dengan upaya peningkatan kinerja penyuluh THL-TBPP, maka perhatian terhadap halhal yang berkaitan dengan pelatihan dan motivasi penyuluh agar dapat terus dipertahankan oleh pemangku kebijakan. Upaya dalam meningkatkan kinerja penyuluh melalui pelatihan dan memberikan motivasi yang baik perlu dilaksanakan secara sinergis dan berkelanjutan. Hal ini dapat dilakukan dengan mengupayakan adanya penganggaran yang memadai melalui dana APBD/APBN sehingga penyuluh THL-TBPP memiliki kesempatan yang sama dalam memperbaiki kompetensinya melalui pelatihan dan meningkatkan motivasinya untuk peningkatan kinerja dalam melakukan penyuluhan pertanian di lapangan. 


\section{DAFTAR PUSTAKA}

[1] Arifianto, S., Satmoko, S., dan Setiawan, B.M. (2017). Pengaruh Karakteristik Penyuluh, Kondisi Kerja, Motivasi terhadap Kinerja Penyuluh Pertanian dan pada Perilaku Petani Padi di Kabupaten Rembang. Agrisocionomics. 1(2): 166-180.

[2] Arikunto. (2009). Prosedur Penelitian, Suatu Pendekatan Praktek. Jakarta: Rineka Cipta.

[3] Creswell, JW. (2010). Research Design, Pendekatan Kualitatif, Kuantitatif, dan Mixed. Yogyakarta ID: Pustaka Belajar.

[4] Dessler, Gary. (2009). Manajemen Sumber Daya Manusia. Jakarta: PT. Prenhalindo.

[5] Elizar, Tanjung, H. (2018). Pengaruh Pelatihan, Kompetensi, Lingkungan Kerja terhadap KinerjaPegawai. Jurnal Ilmiah Magister Manajemen. 1(1): 46-58.

[6] Gallerman, Soul W. (1984). Terjemahan Soepomo S. Wardoyo. Motivasi dan Produktivitas. Jakarta: Pustaka Binaman Pressindo.

[7] Gomes, Faustino Cardoso. (2000). Manajemen Sumber Daya Manusia, Cetakan Keempat. Yogyakarta. Penerbit Andi.

[8] Hamzah, I. (2011). Faktor Penentu Kinerja Penyuluh Pertanian di Kota Tidore Kepulauan Provinsi Maluku Utara. Tesis. Sekolah Pascasarjana IPB. Bogor.

[9] Handoko, T. Hani (2007). Motivasi Daya Penggerak Tingkah Laku. Jakarta: Konsensus.

[10] Handoko, T. Hani (2001). Manajemen Personalia dan Sumberdaya Manusia. Yogyakarta: BPFE.

[11] Hartanto, Hendriani, S, Maulida, Y. (2018). Analisis Pengaruh Kondisi Kerja, Motivasi Kerja, dan Disiplin Kerja Terhadap Kinerja Pegawai Kantor Wilayah Direktorat Jenderal Kekayaan Negara Riau, Sumatera Barat, dan Kepulauan Riau. Jurnal Tepak Manajemen Bisnis. 10(2): 226-241.

[12] Hasibuan, Melayu SP. (2007). Manajemen Sumber Daya Manusia. Jakarta: PT. Gunung Agung.

[13] Helmy, Z., Sumardjo, Purnaningsih, N., Tjitropranoto, P. (2013). Hubungan Kompetensi Penyuluh dengan Karakteristik Pribadi, Persepsi Penyuluh. 